\title{
Analysis of Thorax Injuries in 112 Death Cases Caused by Traffic Accidents
}

\author{
Yanxiang Zhang1,2, Xiaolin Quan², Hui Tang², Yuanwei Lei² \\ ${ }^{1}$ Medical School of Yangtze University, Jingzhou, China \\ ${ }^{2} \mathrm{Chu}$ Xin-Shengyuan Medicolegal Expertise Centre in Jingzhou, Jingzhou, China \\ Email: qi_ci@163.com
}

How to cite this paper: Zhang, Y.X., Quan, X.L., Tang, H. and Lei, Y.W. (2020) Analysis of Thorax Injuries in 112 Death Cases Caused by Traffic Accidents. Yangtze Medicine, 4, 125-131.

https://doi.org/10.4236/ym.2020.42012

Received: May 4, 2019

Accepted: June 26, 2020

Published: June 29, 2020

Copyright $\odot 2020$ by author(s) and Scientific Research Publishing Inc. This work is licensed under the Creative Commons Attribution International License (CC BY 4.0).

http://creativecommons.org/licenses/by/4.0/

\begin{abstract}
Objective: To explore the characteristics and mechanisms of serious injuries of chest caused by road traffic accidents. Methods: Totally 112 autopsy cases with chest injuries in the urban of Jingzhou road traffic accidents were collected. Systematic review and analysis of the general information, postmortem examinations and assessments of chest injury had carried out from Feb. 2016 to Mar. 2018. Results: Average age of the victims was 52.2 years and the ratio of male to female deaths was 2.39:1. The proportion of motor-cyclists and pedestrians increased significantly. The overwhelming majority of accident vehicles were motorcycles and bicycles. Fractures of ribs and pulmonary contusion were the most common injuries. Craniocerebral and abdominal injuries were the most common associated injuries. Conclusion: Fractures of ribs and pulmonary contusion were the most common features of fatal road traffic injuries, often associated with vitreoretinal damage and serious multiple damages. These features reflect the characteristics of great violence in traffic accidents, which provides the evidence of identification of violent injuries.
\end{abstract}

\section{Keywords}

Road Traffic Accidents, Thorax Injuries, Retrospective Analysis, Forensic Pathology

\section{Introduction}

Injuries of the chest are commonly shown as rib fractures, heart and large vascular injuries, lung parenchymal injury, chest compression and asphyxia, etc. Since the 1990s, it is an important cause of death after traumatic brain injury. In the traffic accidents, the chest injury accounted for $44.5 \%$ of the total number of injuries and a quarter of the total number of deaths caused by injuries [1] [2]. According to the World Health Organization's survey data, road traffic accidents 
may become the fifth leading cause of death by 2030 [3], and the most common MOI is traffic accidents according to the statistics of the mechanism of chest wall trauma injury (MOI) among people over the age of 15 [4]. This study systematically reviews and analyzes the general information, cadavers surface examinations and injury assessment of 112 deaths with chest injuries in road traffic accidents, and discusses the characteristics of the chest injury and the mechanism of the injury in fatal traffic accidents, in order to provide a reference for the forensic pathological identification of traffic accidents.

\section{Materials and Methods}

\subsection{Source of Case Data}

Death cases of traffic accidents in Jingzhou area accepted by the author's organization from Feb. 2016 to Mar. 2018 were selected, in which 112 deaths with chest injuries were screened out to collect relevant information including the general data of the deceased, on-site inspection data, medical records and postmortem examination data. The screening conditions are: 1) The autopsy and related examinations confirmed that the cause of death was clear and all due to road traffic accidents. 2) The data was complete. There were complete on-site inspection data, accident spot map, vehicle examination data, trace examination data and relevant clinical data. 3) Each case is subject to on-site inspection, image data and trace examination to clarify the form of the accident and the relationship between the driver and the passenger.

\subsection{Methods}

For the selected cases, the systematic postmortem examination was carried out with reference to "Examination of cadavers surface in forensic medicine" (GA/T149-1996), "Autopsy in forensic medicine" (GA/T147-1996) and "Methods of collecting, fixing, collecting and sending for forensic pathological materials" (GA/T148-1996). Cranial, thoracic, abdominal, pelvic organs were taken conventionally according to the operational specifications for pathological examinations and analysis [5]. The count data was expressed as a percentage.

\section{Results}

\subsection{General Data}

The 112 deaths were aging from 4 to 82 years old, with an average of 52.2 years; there were 79 males (70.54\%) and 33 females (29.46\%), and the ratio of male to female was 2.39:1; the average age of males was 52.94 years old, while that of females was 54.28. The peak of the accidents occurred in July-October each year. There was a sum of 65 deaths in the four months, accounting for $58.04 \%$ of the total deaths in the year.

\subsection{Traffic Mode of the Deceased}

Among the 112 deaths, the proportion of motorcyclists and pedestrians in- 
creased significantly. There were 10 (8.93\%) car drivers and 7 (6.25\%) front (rear) passengers, a total of 17 cases (15.18\%); the number of two-wheel (three-wheel) motorcycle (hereinafter referred to as motorcycles) drivers was 39 $(34.82 \%)$ and that of passengers was $8(7.14 \%)$, a total of 47 cases $(41.96 \%)$; there were $16(14.29 \%)$ bicycle drivers and $3(2.68 \%)$ passengers $(25.89 \%)$; the number of pedestrians was $29(25.89 \%)$. The statistical results of the deaths of various types of traffic mode were shown in Figure 1.

\subsection{Types of Accident-Causing Vehicles}

A total of 166 accident-causing vehicles were involved, and the proportion of motorcycles and small cars increased significantly. Among them, 69 motorcycles accounted for $41.6 \%$, 38 large vehicles for $22.9 \%$, 48 small cars for $28.9 \%$ and 11 bicycles for $0.07 \%$. There were a total of 86 vehicles, accounting for $51.8 \%$.

\subsection{Injuries of Chest}

Among the 112 deaths with the chest injury caused by road traffic accidents, rib fractures (a total of 92 cases, accounting for 82.14\%) and lung contusions (a total of 79 cases, accounting for 70.54\%) were the most common. The proportion of motorcyclists and pedestrians increased significantly. The relationship between the cause of chest injury and different traffic modes was shown in Table 1. Further analysis of rib fractures revealed that bilateral multiple rib fractures were dominant in the deaths by various traffic modes, and most of the deceased were drivers. Among the deaths by motorcycles, bicycles and walking, the proportion of unilateral multiple rib fractures increased significantly. The relationship between rib fractures and different traffic modes was shown in Table 2. Craniocerebral injury and abdominal injury were the most common associated injuries among the 112 deaths. See Table 3 for details of the associated injuries.

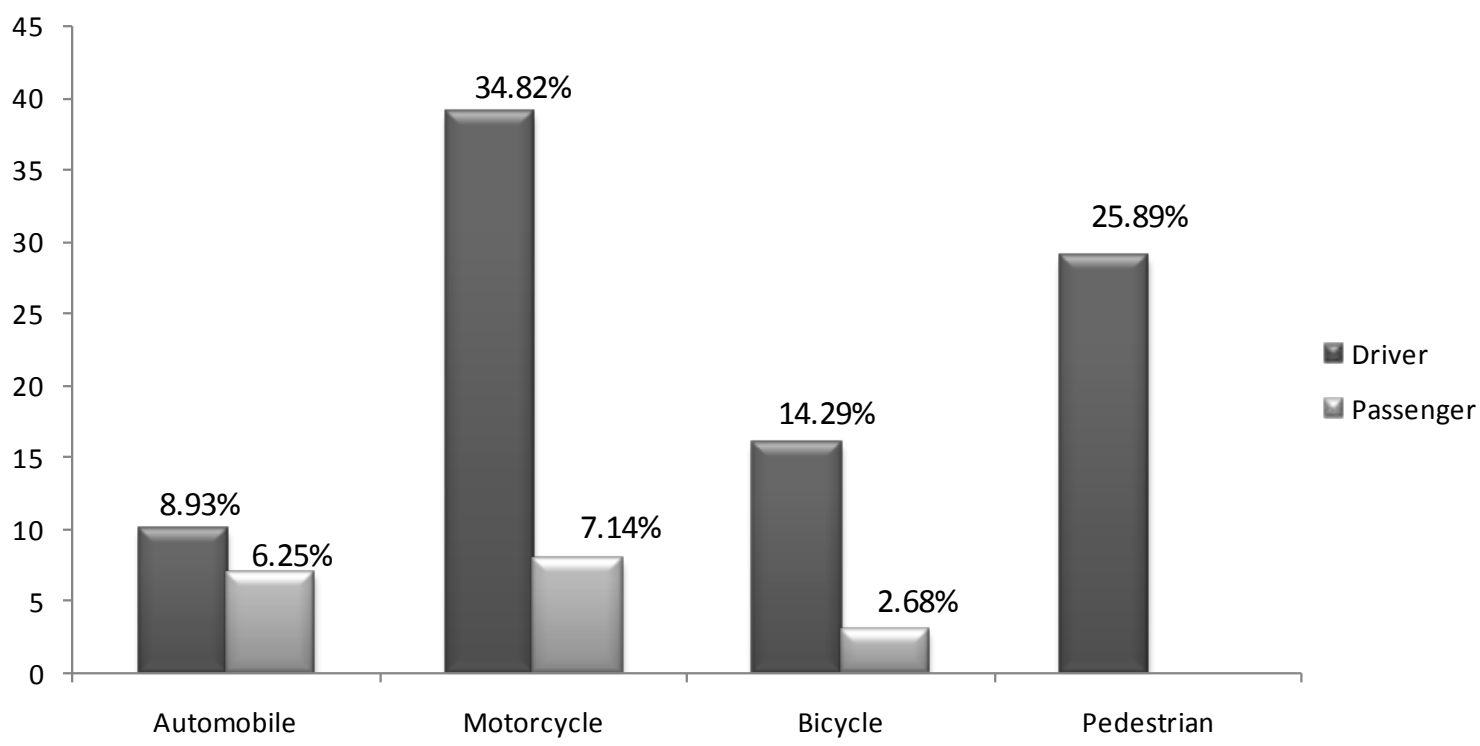

Figure 1. Statistics on the number of deaths by various traffic modes. 
Table 1. Relationship between the cause of chest injuries and different traffic modes.

\begin{tabular}{cccccc}
\hline & \multicolumn{4}{c}{ Traffic mode of the deceased } & \multirow{2}{*}{ Total (\%) } \\
\cline { 2 - 4 } Type of the injury & Automobile & Motorcycle & Bicycle & & \\
\cline { 2 - 4 } & $\begin{array}{c}\text { Driver } \\
\text { (passenger) }\end{array}$ & $\begin{array}{c}\text { Driver } \\
\text { (passenger) }\end{array}$ & $\begin{array}{c}\text { Driver } \\
\text { (passenger) }\end{array}$ & & \\
\hline Rib fracture & $9(3)$ & $38(3)$ & $12(3)$ & 24 & $92(82.14)$ \\
Hemothorax & $3(2)$ & $8(2)$ & $3(1)$ & 6 & $25(22.32)$ \\
Pneumothorax & $3(0)$ & $7(0)$ & $1(1)$ & 4 & $16(14.29)$ \\
hemopneumothorax & $4(2)$ & $17(4)$ & $9(2)$ & 9 & $38(33.93)$ \\
Myocardial contusion & $3(1)$ & $11(3)$ & $3(1)$ & 8 & $30(26.79)$ \\
Cardiac rapture & $6(3)$ & $8(3)$ & $8(2)$ & 10 & $39(34.82)$ \\
Lung contusion & $10(5)$ & $27(7)$ & $8(3)$ & 19 & $79(70.54)$ \\
Lung rapture & $4(3)$ & $18(4)$ & $6(2)$ & 14 & $51(45.54)$ \\
Sterna and clavicle fracture & $4(0)$ & $11(2)$ & $8(2)$ & 3 & $30(26.79)$ \\
Scapular fracture & $3(0)$ & $4(3)$ & $4(1)$ & 4 & $19(16.96)$ \\
Thoracic vertebrae injury & $1(0)$ & $6(3)$ & $3(0)$ & 12 & $25(22.32)$ \\
Thoracic vascular injury & $5(2)$ & $9(2)$ & $5(2)$ & 7 & $32(28.57)$ \\
\hline
\end{tabular}

Table 2. Relationship between the rib fracture and different traffic modes.

\begin{tabular}{cccccc}
\hline & \multicolumn{4}{c}{ Traffic mode of the deceased } & \\
\cline { 2 - 4 } Type of the fracture & Automobile & Motorcycle & Bicycle & Total (\%) \\
\cline { 2 - 4 } & $\begin{array}{c}\text { Driver } \\
\text { (passenger) }\end{array}$ & $\begin{array}{c}\text { Driver } \\
\text { (passenger) }\end{array}$ & $\begin{array}{c}\text { Driver } \\
\text { (passenger) }\end{array}$ & Pedestrian & \\
\hline $\begin{array}{c}\text { Bilateral multiple } \\
\text { rib fractures }\end{array}$ & $7(1)$ & $20(4)$ & $6(1)$ & 14 & $53(47.32)$ \\
$\begin{array}{c}\text { Unilateral multiple } \\
\text { rib fractures }\end{array}$ & $2(1)$ & $8(4)$ & $5(1)$ & 7 & $28(25.00)$ \\
$\begin{array}{c}\text { Unilateral single } \\
\text { rib fracture } \\
\text { Total }\end{array}$ & $0(1)$ & $2(3)$ & $1(1)$ & 3 & $11(9.82)$ \\
\hline
\end{tabular}

Table 3. Relationship between different types of associated injuries and different traffic modes.

\begin{tabular}{cccccc}
\hline \multirow{2}{*}{$\begin{array}{c}\text { Type of the } \\
\text { associated injury }\end{array}$} & \multicolumn{3}{c}{ Traffic mode of the deceased } & & \multirow{2}{*}{ Total (\%) } \\
\cline { 2 - 4 } & Automobile & Motorcycle & Bicycle & & Pedestrian \\
\cline { 2 - 4 } Driver & $\begin{array}{c}\text { Driver } \\
\text { (passenger) }\end{array}$ & $\begin{array}{c}\text { Driver } \\
\text { (passenger) }\end{array}$ & passenger) & & \\
\hline $\begin{array}{c}\text { Associated } \\
\text { craniocerebral injury }\end{array}$ & $9(6)$ & $33(6)$ & $12(2)$ & 23 & $101(90.18)$ \\
$\begin{array}{c}\text { Associated } \\
\text { abdominal injury }\end{array}$ & $6(2)$ & $28(3)$ & $7(2)$ & 17 & $65(58.04)$ \\
$\begin{array}{c}\text { Associated pelvic injury } \\
\text { Associated lower } \\
\text { limbs fracture }\end{array}$ & $1(2)$ & $11(4)$ & $3(1)$ & 6 & $30(26.79)$ \\
Total & $17(12)$ & $61(13)$ & $18(5)$ & 37 & $163(145.54)$ \\
\hline
\end{tabular}




\section{Discussion}

Among the 112 deaths in road traffic accidents, there were significantly more males than females, and the ratio of male to female was 2.39: 1 which is similar to the ratio of male to female deaths in traffic accidents in medium-sized cities in China [6] [7], indicating that there are significantly more males than females in Jingzhou traffic, and males are more likely to die and be injured in road traffic accidents than females. In this study, the average age of drivers was increasing, and the proportion of middle-aged and elderly deaths in accidents was high. This may be due to the rapid increase in the number of motor vehicles in Jingzhou as the economy develops and the purchasing power of the people increases, the decline of reaction ability and body resistance of middle-aged and elderly people, as well as their lack of road traffic safety consciousness.

From the traffic modes of the deceased and the types of vehicles involved, pedestrians and motorcyclists have become the most vulnerable road users, and the injuries are mainly caused by small cars and motorcycles. The analysis indicates that it is related to the rapid increase in the purchase of small cars and the fact that the use of motorcycles (electric motorcycles) was not effectively controlled in Jingzhou. The lack of education on road traffic safety consciousness and the inability to keep up with the progress of traffic modes are also important causes of accidents.

Chest trauma accounts for up to $10 \%-15 \%$ of all traumas, and in the world, the chest trauma accounts for $25 \%$ of the death cases caused by trauma [8]. The chest trauma caused by road traffic accidents is mainly blunt trauma, the onset is acute, the condition changes rapidly, and the breathing disorder is obvious; the death is often caused due to the huge violence injury, severe injury and delayed treatment. Among the death cases caused by chest trauma in the literature, motor vehicle collisions accounted for about $60 \%-70 \%$, while this proportion was higher in developing countries [9] [10]. This study found that among the 112 deaths with the chest injury caused by road traffic accidents, rib fractures and lung contusions were the most common. The analysis of rib fractures revealed that bilateral multiple rib fractures were dominant in the deaths and most of the deceased were drivers. Among the deaths by motorcycles, bicycles and walking, the proportion of unilateral multiple rib fractures increased significantly, which is consistent with the domestic literature report [6]. The mechanism can reflect the mixed huge violence intensity of road traffic accidents, according to which the chest trauma caused by other reasons is distinguished. Significantly, in this study, no rupture of the diaphragm or rupture of the esophagus and airway was found in the 112 cases of chest injury caused by road traffic accidents, suggesting that such separate injuries are less common under the protection of the chest bones.

In addition to chest injuries, the 112 deaths in road traffic accidents often have associated injuries, most common in head and abdomen injuries. Most of them 
have characteristics of light injury on one side of the body and heavy injury on the other side. Within this study, the motorcyclist's associated injury was particularly prominent. The head, abdomen, pelvis and lower limb injuries were not uncommon. It suggests that for the relevant population, the possibility of the multi-system and multi-organ combined injury should be highly valued during emergency treatment, and the corresponding treatment measures should also be developed.

In view of the wide range of injuries caused by traffic accidents, the complex injuries and the most common joint injuries of multiple organ systems, the identification of injuries in cadavers surface and autopsy examinations has great limitations. It is still necessary to combine the vehicle, trace and on-site examinations and other comprehensive analyses to lead to objective and true identification results.

\section{Conflicts of Interest}

The authors declare no conflicts of interest regarding the publication of this paper.

\section{References}

[1] Cong, B. (2016) Forensic Pathology. 5th Edition, People's Medical Publishing House, Beijing, China.

[2] Chien, C.-Y., Chen, Y.-H., Han, S.-T., Blaney, G.N., Huang, T.-S. and Chen, K.-F. (2017) The Number of Displaced Rib Fractures Is More Predictive for Complications in Chest Trauma Patients. Scandinavian Journal of Trauma, Resuscitation and Emergency Medicine, 25, 19. https://doi.org/10.1186/s13049-017-0368-y

[3] Caragounis, E.C., Xiao, Y. and Granhed, H. (2019) Mechanism of Injury, Injury Patterns and Associated Injuries in Patients Operated for Chest Wall Trauma. European Journal of Trauma and Emergency Surgery, 1-10. https://doi.org/10.1007/s00068-019-01119-z

[4] Ernstberger, A., Joeris, A., Daigl, M., Kiss, M., Angerpointner, K., Nerlich, M. and Schmucker, U. (2015) Decrease of Morbidity in Road Traffic Accidents in a High Income Country-An Analysis of 24,405 Accidents in a 21 Year Period. Injury, 46, S135-S143. https://doi.org/10.1016/S0020-1383(15)30033-4

[5] Chinese Medical Association (2004) Clinical Practice Specification: Pathology. People's Military Medical Publisher, Beijing.

[6] Zhang, W., Jiang, D.-S. and Geng, G.-J. (2016) Characteristics of Rib Fractures in 130 Traffic Accident Deaths. Chinese Journal of Forensic Medicine, 31, 614-617.

[7] Qiu, J.-L., Li, K., Su, S., Liu, W.-J. and Yin, Z.-Y. (2017) Injury Analysis of Drivers and Passengers in Motorcycle Accidents in Chongqing Area. Chong Qing Medicine, 46, 3103-3105.

[8] O’Connor, J.V. and Adamski, J. (2010) The Diagnosis and Treatment of Non-Cardiac Thoracic Trauma. Journal of the Royal Army Medical Corps, 156, 5-14. https://doi.org/10.1136/jramc-156-01-02

[9] El-Menyar, A., Abdelrahman, H., Al-Hassani, A., Ellabib, M., Asim, M., Zarour, A. and Al-Thani, H. (2016) Clinical Presentation and Time-Based Mortality in Patients 
with Chest Injuries Associated with Road Traffic Accidents. Archives of Trauma Research, 5, e31888. https://doi.org/10.5812/atr.31888

[10] Mamtani, R., Al-Thani, M.H., Al-Thani, A.A., Sheikh, J.I. and Lowenfels, A.B. (2012) Motor Vehicle Injuries in Qatar: Time Trends in a Rapidly Developing Middle Eastern Nation. Injury Prevention, 18, 130-132.

https://doi.org/10.1136/injuryprev-2011-040147 